\title{
Opioids and pharmacare top of mind at annual CADTH meeting
}

\author{
Cite as: CMAJ 2018 May 7;190:E577. doi: 10.1503/cmaj.109-5596
}

Posted on cmajnews.com on Apr. 18, 2018.

$\mathbf{T}$ he annual meeting of the Canadian Agency for Drugs and Technology in Health (CADTH) took place between a pharmacy conference and the annual meeting of the Liberal Party of Canada, which was scheduled to debate a resolution on establishing a national pharmacare plan. It was fitting, then, that much of the discussion at the CADTH meeting focused on pharmacare and the options for implementing a national drug plan.

Dr. Brian O'Rourke, CADTH's CEO and president, said part of the agency's new strategic plan includes a commitment to support the federal government in whatever it decides about a national drug plan. "I want to go into this with an open mind," said O'Rourke.

According to John Abbott, deputy minister of health for Newfoundland and Labrador, figuring out pharmacare is a top priority. "There's no doubt in my mind it's something we have to move forward to achieve," he said in the opening session.

Speakers at the meeting provided various perspectives on maintaining appropriate, affordable and accessible drug therapy in Canada. Panelists included Dr. Steve Morgan, professor of population and public health at the University of British Columbia, who has researched the cost savings possible from a publicly funded list of essential drugs in Canada. Morgan stressed the importance of ensuring publicly funded medications are used appropriately and result in improved care. During another session, there was discussion about a randomized controlled trial underway at four sites in Ontario to test the value of making essential medications free-of-charge to primary care patients.
As the agency charged with making recommendations at the federal level about the efficacy of new drugs and whether they should be funded, CADTH held several sessions at its annual meeting that focused on various issues involving and BC we haven't seen that abate yet," said Milton Sussman, deputy minister of health for Alberta. "I think we're still not fully understanding the complexity of the problem, and that is going to take some time."

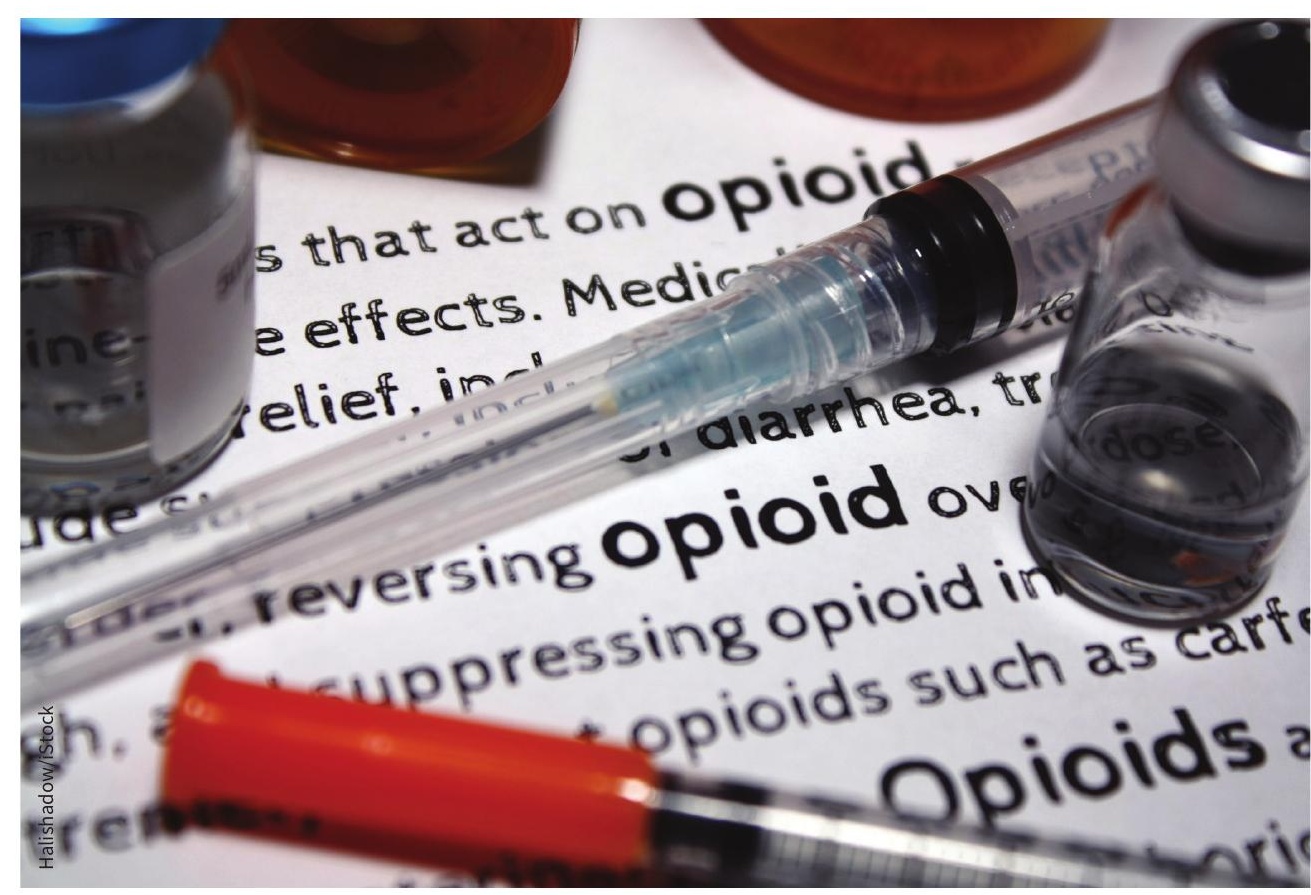

It may take time to understand fully the complexity of the opioid crisis, according to deputy health ministers.

pharmaceuticals in addition to pharmacare. These topics included treatments for rare diseases, antimicrobial-resistant drugs and opioids.

The opioid crisis, in particular, was a major topic of discussion, beginning with the opening session, which featuring a panel of deputy health ministers. "I think it's too early to say if we can end the crisis. Certainly the deaths are still increasing, and certainly in both Alberta
Another health minister suggested the physician community continues to prescribe opioids at a questionable rate. Other sessions and posters at the conference detailed specific initiatives to reduce inappropriate prescribing of opioids, evaluate emerging drugs to treat opioid addiction and develop a national opioid strategy.

Pat Rich, Ottawa, Ont. 